\section{Viral meningitis}

\author{
Sarah A E Logan, Eithne MacMahon
}

Infection and Immunology, Guy's and St Thomas' NHS Foundation Trust, London SE1 7EH

Correspondence to: $\mathrm{E}$ MacMahon eithne.macmahon@gstt.nhs.uk

BMJ 2008;336:36-40 doi:10.1136/bmj.39409.673657.AE
Viral meningitis is common and often goes unreported. In the absence of a lumbar puncture, viral and bacterial meningitis cannot be differentiated with certainty, and all suspected cases should therefore be referred. Lumbar puncture and analysis of cerebrospinal fluid may be done primarily to exclude bacterial meningitis, but identification of the specific viral cause is itself beneficial. Viral diagnosis informs prognosis, enhances care of the patient, reduces the use of antibiotics, decreases length of stay in hospital, and can help to prevent further spread of infection. Over the past 20 years, vaccination policies, the HIV epidemic, altered sexual behaviour, and increasing travel have altered the spectrum of causative agents. In this review we outline the changing epidemiology, discuss key clinical topics, and illustrate how identification of the specific viral cause is beneficial. Neonatal meningitis may be a component of perinatal infection and is not covered here.

\section{How common is viral meningitis?}

Viral meningitis can occur at any age but is most common in young children. In the largest reported study, a 1966 birth cohort of 12000 children in Finland, the annual incidence of presumed viral meningitis was 219 per 100000 in infants under 1 year and 27.8 per 100000 overall in children under $14 .^{4}$ In a smaller retrospective study, the incidence of aseptic meningitis in people aged 16 and over was lower at 7.6 per $100000 .^{5}$

Viral meningitis is a notifiable disease in England and Wales, but many cases undoubtedly go unreported. ${ }^{467}$ In 2005-6, 2898 people were admitted to hospital with a diagnosis of viral meningitis, 10 times the number of cases notified to the Health Protection Agency (233) for England and Wales over the same period (fig 1). ${ }^{78}$

\section{What causes it?}

As a consequence of mumps, measles, and rubella vaccination, enteroviruses have supplanted mumps as the most common cause of viral meningitis in children (box 1). ${ }^{46}$ Enteroviruses are said to account for $80 \%$ of cases in adults, but a wider range of causes is increasingly implicated. ${ }^{59}$ Often no cause is identified; among 144 consecutive adults with aseptic meningitis, only 72 had a confirmed diagnosis. Enteroviruses were most common, accounting for $46 \%$, followed by herpes simplex virus type $2(31 \%)$, varicella zoster virus $(11 \%)$, and herpes simplex virus type $1(4 \%) .{ }^{5}$

\section{What is the initial approach to the patient?}

Viral meningitis and bacterial meningitis are both characterised by acute onset of fever, headache, photophobia, and neck stiffness, often accompanied by nausea and vomiting. ${ }^{19}$ Untreated patients with bacterial meningitis show progressive deterioration in mental status, whereas spontaneous recovery is usual in viral cases. At initial presentation, no reliable clinical indicators are available to differentiate between acute viral meningitis and bacterial meningitis, so all suspected cases should be referred to hospital.

Particular caution is warranted with young children, in whom meningitis is manifest as fever and irritability, without, as a rule, evidence of meningeal irritation. ${ }^{9}$ Neck stiffness and photophobia may also be absent in adults. ${ }^{10}$ Assessment should include evaluation for possible encephalitis, suggested by seizures, reduced Glasgow coma score, or focal neurological signs. Suspected encephalitis warrants empirical antiviral treatment with intravenous aciclovir. History and examination can yield clues as to viral causes (box 2).

\section{Definitions}

Meningitis-Inflammation of the meninges associated with an abnormal number of cells in the cerebrospinal fluid $^{1}$

Aseptic meningitis-A syndrome characterised by acute onset of meningeal symptoms and fever, with pleocytosis of the cerebrospinal fluid and no growth on routine bacterial culture ${ }^{2}$

Mononuclear pleocytosis-An elevated white cell count in the cerebrospinal fluid, with predominant mononuclear cells (as opposed to polymorphonuclear leucocytes)

Encephalitis-Inflammation of the brain parenchyma; cerebral cortex disease causes altered mental status early in the course, and focal or diffuse neurological signs may be present ${ }^{13}$

Meningoencephalitis-Central nervous system infection with clinical features of both meningeal and parenchymal disease 


\section{Sources and selection criteria}

We searched PubMed with the terms "viral", "encephalitis", "HIV", "Herpes simplex", "Mumps", "Varicella", "Enterovirus", "Diagnosis", and "immunosuppression”, in conjunction with meningitis. We also searched OVID, Embase, and Cochrane databases. We hand searched references from papers. For clinical guidelines, we accessed the websites of the UK Health Protection Agency, UK Department of Health, US Centers for Disease Control and Prevention, and World Health Organization. We also consulted several formal medical, infectious diseases, and virological textbooks.

\section{How is it diagnosed?}

Analysis of cerebrospinal fluid is needed, and lumbar puncture should be done unless it is contraindicated. Whether prior computed tomography imaging is needed is controversial, and guidance is now available (see box 2). ${ }^{112}$ Viral meningitis in itself is not associated with abnormalities on imaging. $\mathrm{C}$ reactive protein concentration and peripheral blood white cell count can be helpful but do not reliably differentiate between possible causes. A blood glucose concentration is essential and should be collected immediately before lumbar puncture. ${ }^{3}$ Cerebrospinal fluid needs to be processed promptly to avoid depletion of cell counts during transport or storage. Although characteristically associated with a mononuclear pleocytosis, neutrophils may predominate initially in viral meningitis (table 1). In 138 children with aseptic meningitis, $57 \%$ had a polymorphonuclear predominance that persisted beyond 24 hours. ${ }^{14}$

The usual initial approach to viral diagnosis (table 2) is to test the cerebrospinal fluid for enteroviruses, herpes simplex virus, and varicella zoster virus by using polymerase chain reaction technology, estimated to be threefold to 1000 -fold more sensitive than routine viral culture. ${ }^{15}$ Identification of a viral cause has been shown to be beneficial, facilitating reduced administration of antibiotics and decreased length of stay in hospital. ${ }^{16}$

\section{Enteroviruses}

Enteroviruses are by far the most common cause of viral meningitis; they account for most cases, at all ages, in which the cause is identified..$^{4-69}$ The term enteroviruses refers to the mode of transmission rather than the symptoms of infection. Indeed, infections with these ubiquitous viruses are mostly asymptomatic. They can cause systemic infections, however, and have a proclivity to be neuroinvasive. The enteroviruses

\begin{tabular}{|c|c|c|c|c|}
\hline $\begin{array}{l}\text { Cause of } \\
\text { meningitis }\end{array}$ & $\begin{array}{l}\text { White blood cell count } \\
\text { (cells/mm3/106 cells/l) }\end{array}$ & $\begin{array}{l}\text { Predominant } \\
\text { cell type }\end{array}$ & $\begin{array}{l}\text { CSF: serum glucose } \\
\quad(\text { normal } \geq 0.5)\end{array}$ & $\begin{array}{c}\text { Protein (g/l) } \\
\text { (normal } 0.2-0.4 \text { ) }\end{array}$ \\
\hline Viral & $50-1000$ & $\begin{array}{l}\text { Mononuclear (may be } \\
\text { neutrophilic early in } \\
\text { course) }\end{array}$ & $>0.5$ & $0.4-0.8$ \\
\hline Bacterial & $100-5000$ & $\begin{array}{l}\text { Neutrophilic } \\
\text { (mononuclear after } \\
\text { antibiotics) }\end{array}$ & $<0.5$ & $0.5-2.0$ \\
\hline Tuberculous & $50-300$ & Mononuclear & $<0.3$ & $0.5-3.0$ \\
\hline Cryptococcal & $20-500$ & Mononuclear & $<0.5$ & $0.5-3.0$ \\
\hline
\end{tabular}

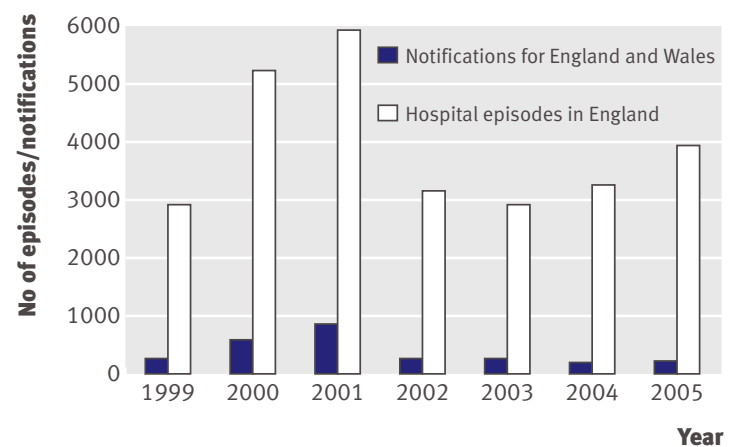

Fig 1 Notifications of viral meningitis for England and Wales compared with hospital episodes in England

encompass Coxsackie A and B viruses, echoviruses, polioviruses, and the more recently identified viruses designated by number, such as enterovirus $71 .{ }^{19}$ Almost any of the enterovirus types can give rise to neurological manifestations ranging from aseptic meningitis to meningoencephalitis and paralytic poliomyelitis. Coxsackie B viruses and echoviruses account for most cases of enterovirus meningitis. Enteroviral typing is essential to identify and monitor outbreaks. ${ }^{19}$

\section{Who gets it?}

Infants and young children with no immunity are most susceptible to enteroviruses, and the incidence decreases with age. Infection is seasonal in temperate climates - highest in summer and autumn — but high all year round in tropical and subtropical climates. ${ }^{9}$

\section{Clinical features and management}

Meningitis may be accompanied by mucocutaneous manifestations of enterovirus infection, including localised vesicles such as in hand, foot, and mouth disease; herpangina; and generalised maculopapular rash. Most cases that present clinically with meningitis are self limiting and carry a good prognosis. Nevertheless, enteroviral meningitis causes considerable morbidity, with moderate or high fever despite antipyretics and several days of severe headache warranting opiate analgesia. ${ }^{10}$ Abrupt deterioration in mental status or seizures may be caused by progression from meningitis to meningoencephalitis. ${ }^{9}$

No specific antiviral treatment is available, and management is conservative. Immunoglobulin replacement has a role in patients with hypogammaglobulinaemia, who are prone to severe and chronic enteroviral disease.

\section{Herpes simplex viruses (HSV-2, HSV-1)}

Confusion sometimes arises when herpes simplex virus is detected in the cerebrospinal fluid of a patient with clinical meningitis. Recognising that herpes simplex virus meningitis and encephalitis are discrete entities in the immunocompetent host, rather than part of a continuous spectrum, is essential. Whereas herpes simplex virus encephalitis is a life threatening medical emergency warranting empiric antiviral treatment, 
Box 1 Viral meningitis: causes to consider ${ }^{139}$

\section{All patients}

- Enteroviruses

- Herpes simplex viruses (HSV-2 and HSV-1)

- Varicella zoster virus (VZV)

- Human immunodeficiency virus (HIV)

- Epstein-Barr virus (EBV)

Unvaccinated/incomplete vaccination course

- Mumps virus

Immunocompromised host

- Cytomegalovirus (CMV)

Travel history

- West Nile virus (Americas, Africa, West Asia, Australia, mainland Europe)

- Saint Louis encephalitis virus (United States)

- Tick-borne encephalitis viruses (mainland Europe and Asia)

Contact with rodent droppings or urine

- Lymphocytic choriomeningitis virus (LCMV)

herpes simplex virus meningitis is a self limiting condition in patients with normal immunity. ${ }^{20}$

\section{Who gets it?}

Herpes simplex virus now ranks second among the causes of viral meningitis in adolescents and adults in developed countries. ${ }^{5}$ Herpes simplex virus meningitis is a complication of primary genital herpes, especially with HSV-2. By definition, primary herpes simplex virus infection is the first infection with either virus type in the absence of pre-existing antibodies to HSV-1 or HSV-2. In the most comprehensive study, 36\% of 126 women and $13 \%$ of 63 men with primary genital HSV-2 infection had meningeal symptoms. ${ }^{21}$

Non-primary infection includes first episodes in the presence of pre-existing antibodies to HSV-1 or HSV-2 and recurrences. Unlike primary infection, nonprimary genital infection with herpes simplex virus is rarely accompanied by aseptic meningitis. HSV-2

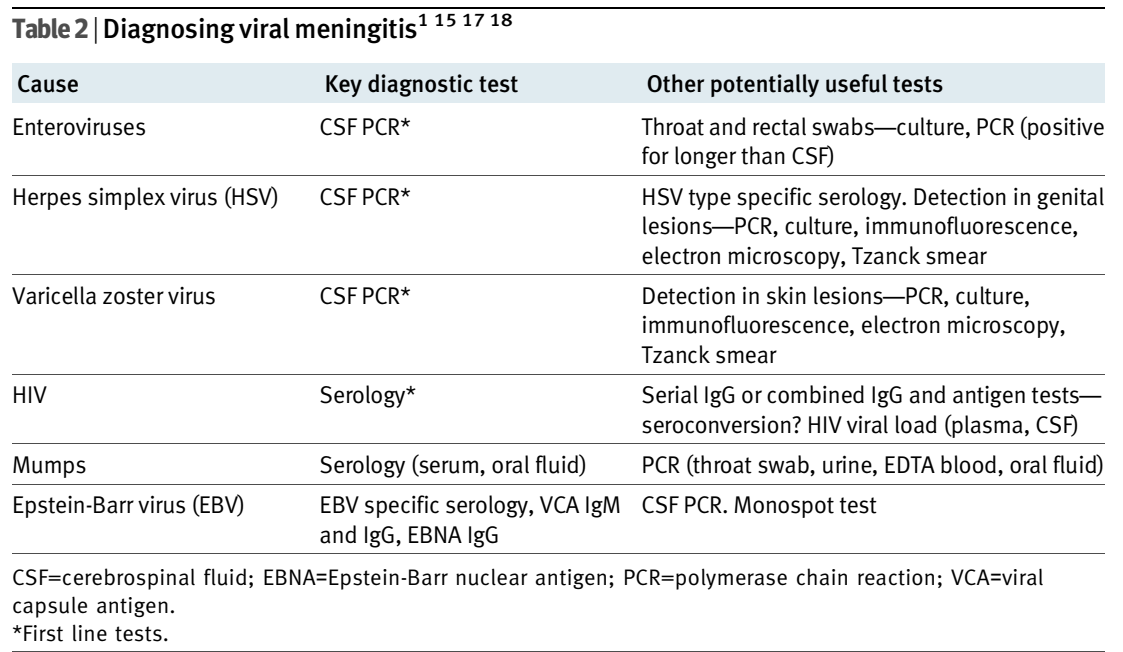

meningitis may also occur in the absence of clinical genital herpes. Of 69 patients with meningeal symptoms and HSV-2 detected in the cerebrospinal fluid, $82 \%$ had neither a history of genital herpes nor active genital lesions. ${ }^{22}$

As a consequence of the increasing incidence of genital herpes, ${ }^{23}$ clinical cases of herpes simplex virus meningitis in the United Kingdom are set to increase. The rate of childhood infection with HSV-1 is declining; a documented drop in seropositivity rates among 10-14 year olds from $34 \%$ (1986-7) to $24 \%$ (1994-5) has occurred. ${ }^{24}$ Thus, in the absence of previous oral herpes simplex virus infection, an increasing proportion of young people are likely to have symptomatic primary genital herpes simplex virus infections and hence meningitis.

Clinical features and management

In addition to fever and symptoms of meningitis, constitutional symptoms of primary herpes infection

\section{Box 2 Approach to the patient}

\section{History}

- Classic symptoms—fever, headache, photophobia, neck stiffness

- Associated symptoms-rash, sore throat, swollen glands, vomiting, genitourinary symptoms

- Illness in contacts

- Sexual history

- Travel abroad

- Risk factors for HIV

- Mumps immunisation status

- Compromised immunity

- Exposure to rodents/ticks

Examination

- Classic signs:

- Fever, nuchal rigidity

- Absence of focal neurological signs; mental status intact

- Risk factors for HIV

- Rash

- Lymphadenopathy

- Pharyngitis

- Parotid swelling

- Genital herpes

Imaging before lumbar puncture?

Recommended if any of the following are present ${ }^{11-13}$

- Immunocompromised host: Immunosuppressive treatment Immunodeficiency (for example, HIV)

- New onset of seizure(s)—within one week of presentation

- Focal neurological deficit

- Abnormal level of consciousness manifest by: Glasgow coma score (GCS) $<12$ or Fluctuating conscious level (drop in $\mathrm{GCS} \geq 2$ ) Papilloedema 
may occur, with malaise and clinical features of genital herpes simplex virus infection. Whereas autonomic dysfunction occurs in $2 \%$ of cases of primary genital herpes, sacral radiculomyelitis (manifest as urinary retention, constipation, paraesthesias, and motor weakness) complicates one third of cases with primary HSV-2 meningitis. ${ }^{21}$

\section{Case studies}

\section{Patient 1}

A 37 year old woman presented with headache, neck stiffness, photophobia, and vomiting. She had been increasingly unwell over the preceding 10 days and had sought medical advice for severe dysuria on more than one occasion; she was receiving treatment for a presumptive urinary tract infection. On examination, she was febrile with signs of meningism. Vulval inspection showed no evidence of vesicles. Analysis of cerebrospinal fluid showed white cells $692 \times 10^{6} / \mathrm{l}(99 \%$ lymphocytes), protein $1.6 \mathrm{~g} / \mathrm{l}$, and glucose $2.8 \mathrm{mmol} / \mathrm{l}$; no concomitant serum sample was available. Polymerase chain reaction detected HSV-2 DNA in the cerebrospinal fluid, consistent with the diagnosis of herpes simplex virus meningitis. She was treated with intravenous aciclovir $10 \mathrm{mg} / \mathrm{kg}$ eight hourly for six days, followed by oral valaciclovir $1 \mathrm{~g}$ eight hourly for two weeks. Her symptoms resolved gradually, and she was discharged after six days.

At the genitourinary clinic two months later, acute and convalescent type specific serology confirmed recent primary HSV-2 (HSV-2 IgG positive; HSV-1 IgG negative; antiHSV IgM positive) infection in association with meningitis and presumed urethritis. Her husband also attended; although asymptomatic, he had serological evidence of previous HSV-2 infection. One year later she has had recurrent genital herpes but not meningitis.

\section{Patient 2}

A 32 year old woman presented with a three day history of headache, fever, and photophobia. She had perianal tenderness, and her boyfriend had noticed a rash. On examination, unilateral herpetic lesions were seen (fig 2). Cerebrospinal fluid showed mononuclear pleocytosis $\left(67 \times 10^{6} / \mathrm{l}\right)$ and protein $1.2 \mathrm{~g} / \mathrm{l}$ and was positive for varicella zoster virus DNA. She received oral valaciclovir $1 \mathrm{~g}$ eight hourly for seven days and opiates for severe headache. Her symptoms gradually resolved over three weeks.

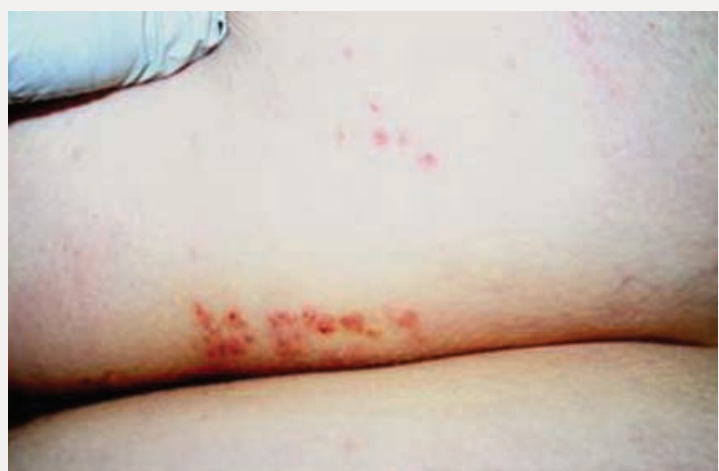

Fig 2 Patient 2-zoster associated with varicella zoster virus meningitis
HSV-2 meningitis can recur, especially in women with primary genital infection. ${ }^{21}$ Clinical recurrences have been described in 20-50\% of cases, both with and without genital symptoms. ${ }^{25}{ }^{26}$ Indeed HSV-2 has been implicated in recurrent benign lymphocytic meningitis (including Mollaret's meningitis), a syndrome characterised by spontaneous recovery after each of at least three episodes of aseptic meningitis. HSV-2 (and occasionally HSV-1) DNA and herpes simplex virus type specific antibodies have been detected in the cerebrospinal fluid of up to $85 \%$ of patients. ${ }^{26}$

Although antiviral treatment with aciclovir, valaciclovir, or famciclovir is indicated for the treatment of first episode genital herpes, therapeutic trials have yet to be done in herpes simplex virus meningitis. ${ }^{20}$ Evidence is lacking, but early treatment might decrease the viral burden, speed resolution of symptoms, and reduce the risk of recurrence.

Patients with herpes simplex virus meningitis should be referred to a sexual health clinic after recovery. However, the diagnosis of herpes simplex virus meningitis and possible associations with genital herpes may come as a shock to the patient, and this needs to be discussed sensitively at the earliest appropriate opportunity. Many people harbour genital herpes simplex virus infection and intermittently shed virus without ever having symptoms. Infection can thus be spread unknowingly to sexual contacts. The timing of transmission is unpredictable; it may occur only after several years within a monogamous sexual relationship. ${ }^{27}$

\section{Varicella zoster virus}

Aseptic meningitis is a recognised but rare complication of primary infection with varicella zoster virus (varicella). It is more commonly seen in association with reactivation of varicella zoster virus (zoster) and can also occur in the absence of cutaneous lesions. Among 21 patients with varicella zoster virus meningitis, more than $50 \%$ had no skin manifestations. ${ }^{28}$ No specific recommendations for varicella zoster virus meningitis exist beyond the usual treatment for zoster.

\section{Human immunodeficiency virus}

Primary HIV infection is an important cause of aseptic meningitis. Symptoms occur in up to $17 \%$ of cases of HIV seroconversion and may be associated with faster disease progression. ${ }^{29}$ Other features of primary HIV infection-lymphadenopathy, rash, dermatitis, gastrointestinal disturbances, oral candidiasis, and pharyngitis - should be sought. Atypical lymphocytes may be seen on the blood film in both primary HIV and Epstein-Barr virus infections (both are causes of viral meningitis). The neurological symptoms generally resolve over several weeks. Early diagnosis may benefit intimate contacts, as the risk of transmission of HIV is greater in the early stages of infection. ${ }^{30}$

\section{Mumps}

Meningitis is by far the most common neurological manifestation of mumps virus infection. Before 


\section{SUMMARY POINTS}

Bacterial and viral meningitis cannot reliably be differentiated clinically, and all suspected cases should be referred to hospital

Viral meningitis is most common in young children; the incidence decreases with age

Enteroviruses are the most common cause at all ages

Although most cases are self limiting, morbidity may be considerable

Herpes simplex virus causes viral meningitis, which may recur

Genital herpes infection may be acquired from a partner after many years within a monogamous relationship

Meningitis is a feature of HIV seroconversion

In the absence of associated encephalitis, the prognosis is usually good

widespread immunisation, mumps was a common cause of meningitis, which occurred in $15 \%$ of patients with mumps. ${ }^{17}$ Mumps meningitis can precede or follow the parotid swelling, and 50\% of cases occur in the absence of parotitis. Meningitis is more common in male than female patients. ${ }^{17}$ The recent epidemic among young adults was associated with more than 100 cases of mumps meningitis in England in 2004-6.

We thank William Tong and Mike Kidd for critical evaluation of the draft manuscript and Alice Gem for secretarial help.

Contributors: SAEL and EMM searched the literature and wrote the manuscript. EMM is the guarantor.

Competing interests: EMM received sponsorship from Aventis Pasteur MSD towards conference attendance in 2002

1 Tunkel AR, Scheld WM. Acute meningitis. In: Mandell GL, Bennett JE, Dolin R, eds. Mandell, Douglas, and Bennett's principles and practice of infectious diseases . 6th ed. Philadelphia: Elsevier Churchill Livingstone, 2005:1083-126.

2 United States Department of Health and Human Services Centers for Disease Control and Prevention. Aseptic meningitis 1990 case definition. www.cdc.gov/epo/dphsi/casedef/asmeningitiscurrent. htm.

3 Cassady KA, Whitley RJ. Pathogenesis and pathophysiology of viral infections of the central nervous system. In: Scheld WM, Whitley RJ, Marra CM, eds. Infections of the central nervous system . 3rd ed. Philadelphia: Lippincott Williams \& Wilkins, 2004:57-74.

4 Rantakallio $P$, Leskinen $M$, Von Wendt L. Incidence and prognosis of central nervous system infections in a birth cohort of 12,000 children. Scand J Infect Dis 1986;18:287-94.

\section{ADDITIONAL EDUCATIONAL RESOURCES}

World Health Organization (www.who.int/topics/en/)—Links to information on viral diseases and worldwide incidence

Health Protection Agency (www.hpa.org.uk/topics/index_i.htm)—Links to information about viral meningitis

Health Protection Agency (www.hpa.org.uk/cfi/lab_index.htm)—Details of diagnostic laboratories

US Centers for Disease Control (www.cdc.gov)—Links to US information on viral meningitis Information for patients

The Meningitis Trust (www.meningitis-trust.org)—Clear information and fact sheet on viral meningitis

US Centers for Disease Control. Viral "aseptic" meningitis (www.cdc.gov/ncidod/dvrd/revb/ enterovirus/viral_meningitis.htm)—Explains enteroviral meningitis well

Meningitis Research Foundation (www.meningitis.org.uk)—Information mainly about bacterial meningitis
5 Kupila L, Vuorinen T, Vainionpää R, Hukkanen V, Marttila RJ, Kotilainen P. Etiology of aseptic meningitis and encephalitis in an adult population. Neurology 2006;66:75-80.

6 Davison KL, Ramsay ME. The epidemiology of acute meningitis in children in England and Wales. Arch Dis Child 2003;88:662-4.

7 Health Protection Agency. Diseases notifiable (to Local Authority Proper Officers) under the Public Health (Infectious Diseases) Regulations 1988. www.hpa.org.uk/infections/topics_az/noids/ noidlist.htm.

8 HESonline. Hospital episode statistics. www.hesonline.nhs.uk/ Ease/servlet/ContentServer?sitelD=1937\&categorylD=537.

9 Sawyer $\mathrm{MH}$, Rotbart $\mathrm{H}$. Viral meningitis and aseptic meningitis syndrome. In: Scheld WM, Whitley RJ, Marra CM, eds. Infections of the central nervous system. 3rd ed. Philadelphia: Lippincott Williams \& Wilkins, 2004:75-93.

10 Rotbart HA, Brennan PJ, Fife KH, Romero JR, Griffin JA, McKinlay MA, et al. Enterovirus meningitis in adults. Clin Infect Dis 1998;27:896-8.

11 Hasbun R, Abrahams J, Jekel J, Quagliarello VJ. Computed tomography of the head before lumbar puncture in adults with suspected meningitis. N Engl J Med 2001;345:1727-33.

12 Tunkel AR, Hartman BJ, Kaplan SL, Kaufman BA, Roos KL, Scheld WM, et al. Practice guidelines for the management of bacterial meningitis. Clin Infect Dis 2004;39:1267-84.

13 Meningitis Research Foundation. Early management of suspected bacterial meningitis and meningococcal septicaemia in immunocompetent adults. 2nd ed. www.meningitis.org/assets/pdf/ health_professionals/Adult\%20early\%20management\%20poster \%20Dec\%2004.pdf.

14 Negrini B, Kelleher KJ, Wald ER. Cerebrospinal fluid findings in aseptic versus bacterial meningitis. Pediatrics 2000;105:316-9.

15 Read SJ, Kurtz JB. Laboratory diagnosis of common viral infections of the central nervous system by using a single multiplex PCR screening assay. J Clin Microbiol 1999;37:1352-5.

16 Ramers C, Billman G, Hartin M, Ho S, Sawyer MH. Impact of a diagnostic cerebrospinal fluid enterovirus polymerase chain reaction test on patient management. JAMA 2000;283:2680-5.

17 Gupta RK, Best J, MacMahon E. Mumps and the UK epidemic 2005 BMJ 2005;330:1132-5.

18 Health Protection Agency. ERNVL reference and diagnostic testing services. www.hpa.org.uk/cfi/vrd/ernvl/testing.htm.

19 Pallansch MA, Roos RP. Enteroviruses: polioviruses, coxsackieviruses, echoviruses, and newer enteroviruses. In: Knipe DM, Howley PM, Griffin DE, Lamb RA, Martin MA, Roizman B, et al, eds. Fields virology . 4th ed. Philadelphia: Lippincott Williams \& Wilkins, 2001:723-75.

20 Whitley RJ. Herpes simplex virus. In: Scheld WM, Whitley RJ, Marra CM, eds. Infections of the central nervous system . 3rd ed. Philadelphia: Lippincott Williams \& Wilkins, 2004:123-44.

21 Corey L, Adams HG, Brown ZA, Holmes KK. Genital herpes simplex virus infections: clinical manifestations, course, and complications. Ann Intern Med 1983;98:958-72.

22 O'Sullivan CE, Aksamit AJ, Harrington JR, Harmsen WS, Mitchell PS, Patel R. Clinical spectrum and laboratory characteristics associated with detection of herpes simplex virus DNA in cerebrospinal fluid. Mayo Clin Proc 2003;78:1347-52.

23 Health Protection Agency. Trends in genital warts and genital herpes diagnoses in the United Kingdom. Health Protection Report 2007;1(35):4-9 (www.hpa.nhs.uk/hpr/archives/2007/hpr3507. pdf).

24 Vyse AJ, Gay NJ, Slomka MJ, Gopal R, Gibbs T, Morgan-Capner P, et al. The burden of infection with HSV-1 and HSV-2 in England and Wales: implications for the changing epidemiology of genital herpes. Sex Transm Inf 2000;76:183-7.

25 Bergstrom T, Vahine A, Alestig K, Jeansson S, Forsgren M, Lycke E. Primary and recurrent herpes simplex virus type 2-induced meningitis. J Infect Dis 1990;162:322-30.

26 Shalabi M, Whitley RJ. Recurrent benign lymphocytic meningitis. Clin Infect Dis 2006;43:1194-7.

27 Kulhanjian JA, Soroush V, Au DS, Bronzan RN, Yasukawa LL, Weylman LE, et al. Identification of women at unsuspected risk of primary infection with herpes simplex virus type 2 during pregnancy. N Engl J Med 1992;326:916-20.

28 Echevarría JM, Casas I, Tenorio A, de Ory F, Martínez-Martin P. Detection of varicella-zoster virus-specific DNA sequences in cerebrospinal fluid from patients with acute aseptic meningitis and no cutaneous lesions. J Med Virol 1994;43:331-5.

29 Boufassa F, Bachmeyer C, Carre N, Deveau C, Persoz A, Jadand C, et al. Influence of neurologic manifestations of primary human immunodeficiency virus infection on disease progression. J Infect Dis 1995;171:1190-5.

30 Brenner BG, Roger M, Routy IP, Moisi D, Ntemgwa M, Matte C, et al. High rates of forward transmission events after acute/early HIV-1 infection. J Infect Dis 2007;195:951-9. 